\title{
Rabaska
}

Revue d'ethnologie de l'Amérique française

\section{Chaire UNESCO en patrimoine culturel (Université Laval)}

\section{Cyril Simard}

Volume 3, 2005

URI : https://id.erudit.org/iderudit/201745ar

DOI : https://doi.org/10.7202/201745ar

Aller au sommaire du numéro

Éditeur(s)

Société québécoise d'ethnologie

ISSN

1703-7433 (imprimé)

1916-7350 (numérique)

Découvrir la revue

Citer ce document

Simard, C. (2005). Chaire UNESCO en patrimoine culturel (Université Laval). Rabaska, 3, 208-210. https://doi.org/10.7202/201745ar d'utilisation que vous pouvez consulter en ligne.

https://apropos.erudit.org/fr/usagers/politique-dutilisation/ 
Chaire UNESCO en patrimoine culturel Université Laval

Téléphone : (418) 656-5044 Édifice du Vieux Séminaire de Québec Télécopieur : (418) 656-3325 1, Côte de la Fabrique Courriel : cyril.simard@faaav.ulaval.ca Bureau 1222 Québec (Québec) G1K 7P4

Lors de la précédente parution de Rabaska en 2004, nous avions évoqué 
quelque peu notre projet d'établir à Québec le centre nerveux de la formation en patrimoine culturel pour les journalistes du patrimoine mondial. C'est fait : un premier atelier de formation s'est tenu du 23 au 31 mai 2005 avec un succès inespéré. Dix pays représentés, en provenance de quatre continents, en plus de quatre étudiants post-doctoraux du Québec, composaient cet ensemble de journalistes hautement qualifiés qui représentaient des journaux importants de leur pays. Des actes de cet événement important seront publiés, assortis d'un grand nombre de photos. Plusieurs cours seront également offerts par voie de téléviseurs et sur la toile.

Mais voici pour le moment les trois résolutions issues de l'atelier international « Journalisme et patrimoine mondial », tenu à l'Université Laval, Québec. Les participants ont résolu :

1. Atelier annuel et programme de formation. Que l'atelier international sur le journalisme et le patrimoine mondial, le premier du genre dans le monde universitaire francophone - et peut-être anglophone aussi devienne un événement annuel, jusqu'à la mise en place par l'Université Laval d'un programme formel de formation en journalisme et patrimoine devant donner lieu à la délivrance d'un diplôme de deuxième, voire de troisième cycle. Le recteur de l'Université Laval, M. Michel Pigeon a, d'une part, fortement soutenu l'idée de la tenue annuelle de l'atelier international et, d'autre part, recommandé aux instances compétentes de l'université de poursuivre la réflexion sur la création d'un programme de formation dans le domaine du journalisme et du patrimoine.

2. Comité provisoire, associations nationales et réseau international. Que les journalistes provenant des dix pays et quatre continents participant au premier atelier international sur le journalisme et le patrimoine mondial forment un comité provisoire ayant pour mission : premièrement, d'aider à la mise en place d'une association des journalistes du patrimoine au niveau de chaque pays participant ; deuxièmement, d'organiser une assemblée générale constitutive d'un réseau international des associations des journalistes du patrimoine, dans le cadre de la tenue du prochain atelier international sur le journalisme et le patrimoine mondial à Québec ; troisièmement, de maintenir la collaboration avec les universitaires et experts du patrimoine à travers le monde, qui deviendront des partenaires du réseau international en gestation.

3. Rôle de leadership de l'Université Laval. Que l'Université Laval continue de servir d'intermédiaire entre les journalistes, les écoles de journalisme et les spécialistes du patrimoine. À cet effet, l'Université Laval créera, à travers un site électronique hébergé par son département d'Information 
et de communication, un espace de discussion et d'échange entre ces acteurs du patrimoine. L'Université Laval assistera sur le plan logistique le comité provisoire dans le processus d'élection de son bureau de direction et assumera la permanence de son secrétariat à Québec, Canada.

Cette expérience nouvelle montre que le réseautage établi entre la Chaire UNESCO, le département d'Information et de communication de la faculté des Lettres et l'UNESCO a donné des résultats qui seront durables et permanents pour «donner un avenir à la mémoire », tel que le propose la devise de la Chaire UNESCO en patrimoine culturel.

A cette occasion, Mme Marielle Richon, du Centre du patrimoine mondial de l'UNESCO, et notamment responsable du réseau Forum UNESCO Université et Patrimoine, a reçu la médaille de la Chaire UNESCO en patrimoine culturel de l'Université Laval à Québec. Décernée annuellement, cette médaille est attribuée en reconnaissance des contributions exceptionnelles d'une personne à la cause du patrimoine culturel.

CYril Simard 